\title{
Study of Conjunctival Flora in Patients after Peripheral Blood Stem Cell Transplantation and its Correlation with Tear Secretion
}

\author{
Shin-Yi Chen ${ }^{1}$, Ming-Chung Kuo ${ }^{2}$, Po-Nan Wang ${ }^{2}$, Tung-Liang Lin ${ }^{2}$, David Hui-Kang $\mathrm{Ma}^{1}$
}

Background: Dry eye is a major ocular complication of peripheral blood stem cell transplantation (PBSCT) and may predispose bacterial colonization to the conjunctiva. To investigate the conjunctival bacterial flora in patients receiving PBSCT, we encompassed patients who received PBSCT at least 1 year from 2002 to 2008 in this cross-sectional study.

Methods: Patients were divided into three groups in accordance to the result of the Schirmer Ia test. In the control group, we enrolled dry-eye patients with underlying disease other than hematopoietic stem cell transplantation of which the age range was similar to the study group.

Results: Thirty-six patients with 72 eyes were included in our study. The culture rates were $22 \%$ (8 in 36) in the first group (Schirmer Ia $=0-5 \mathrm{~mm}$ ), 20\% (4 in 20) in the second group (Schirmer Ia $=6-9 \mathrm{~mm})$, and $0 \%(\mathrm{n}=16)$ in the third group (Schirmer Ia $\geqq 10 \mathrm{~mm}$ ). The flora in patients receiving PBSCT were coagulase-negative Staphylococci, Staphylococcus aureus and Corynebacterium sp. The bacterial colonization rate in the post-PBSCT group was not higher than the control group (22.2\% vs. $30.8 \%)$, and

\begin{abstract}
At a Glance Commentary
Scientific background of the subject

Dry eye occurs in $40-76 \%$ of post-peripheral blood stem cell transplantation (PBSCT) patients. The rate of positive conjunctival swab cultures in dry eye patients increases when compared with normal control, and the mean bacterial count is positively correlated with the reduction in goblet cells.

\section{What this study adds to the field}

There is a positive correlation between the colonization rate and the severity of dry eye in post-PBSCT patients.

Coagulase-negative Staphylococci is the most common colonizing bacteria of the ocular surface in both the normal population and post-PBSCT patients. The spectrum of conjunctival flora is independent of patient immune status.
\end{abstract} coagulase-negative Staphylococci was the most common flora in the control group.

Conclusions: In conclusion, despite not having statistical significance, there seems to be a positive correlation between the colonization rate and the severity of dry eye. However, bacterial profile isolated in postPBSCT patients is not significantly different from other dry eye patients.

(Biomed J 2012;35:493-99)

Key words: bone marrow transplantation, dry eye, graft-versus-host disease, ocular flora, peripheral blood stem cell transplantation

A llogeneic stem cell transplantation is a known curative treatment for many hematological diseases. The sources of hematopoietic stem cell consist of bone marrow, cord blood, and peripheral blood stem cells. Peripheral blood stem cell transplantation (PBSCT) has gained popularity since their initial introduction in the 1980s. However, al- logeneic stem cell transplantation is a risky procedure with many complications.

Dry eye is the most frequent ocular complication postPBSCT and occurs in $40-76 \%$ of patients. ${ }^{[1-3]}$ The pathogenesis of post PBSCT-associated dry eye may be related to the interaction between CD34+ stromal fibroblasts in the lacrimal

From the ${ }^{1}$ Department of Ophthalmology, Chang Gung Memorial Hospital at Linkou, Chang Gung University College of Medicine, Taoyuan, Taiwan, ${ }^{2}$ Division of Hematology-Oncology, Department of Internal Medicine, Chang Gung Memorial Hospital at Linkou, Chang Gung University College of Medicine, Taoyuan, Taiwan

Received: Apr. 27, 2011; Accepted: Sep. 29, 2011

Correspondence to: Dr. David Hui-Kang Ma, Department of Ophthalmology, Chang Gung Memorial Hospital at Linkou. 5, Fuxing St., Guishan, Taoyuan 333, Taiwan (R.O.C.). Tel: 886-3-3281200 ext. 8652; Fax: 886-3-3287798; E-mail: davidhkma@yahoo.com

DOI: $10.4103 / 2319-4170.104402$ 
gland and T-cells infiltrating into the periductal area, resulting in prominent fibrosis in the lacrimal gland and subsequent secondary lacrimal gland deficiencies. ${ }^{[4]}$

Dry eye is also one of the major risk factors of infectious keratits. ${ }^{[5]}$ The rate of positive conjunctival swab cultures in dry eye patients increases when compared with normal control, and the mean bacterial count is positively correlated with the reduction in goblet cells. ${ }^{[6-8]}$ Because human tear film plays an important role in protecting the ocular surface against various pathogens, ${ }^{[9,10]}$ dry eye in post-PBSCT patients may lead to changes in the components of the tear film, including natural bacteriocidal proteins like lactoferrin. Such changes may predispose bacterial colonization on the conjunctiva.

Some studies indicated that immunocompromised status such as diabetes mellitus, ${ }^{[5,11]}$ administration of immunosuppressive agents ${ }^{[11]}$ and HIV infection, ${ }^{[12]}$ are predisposing factors of microbial keratitis. Consequently, we presumed that the immunosuppressive treatment posthematopoietic stem cell transplantation may also increase the risk of infectious keratitis. Kim et al, reported that the culture-positive rate of MRSA in conjunctiva was significantly higher in ICU-stayed children who later developed keratitis. ${ }^{[13]}$ Therefore, periodic surveillance of conjunctiva flora may be helpful to prevent infectious keratitis in immunocompromised post-PBSCT patients. The aim of this study is to investigate the conjunctival bacterial flora in post-PBSCT patients and its correlation with the tear secretion.

\section{METHODS}

\section{Patient selection}

The project to study the conjunctival bacterial flora in post-PBSCT patients was first approved by the Institution Review Board of Chang Gung Memorial Hospital, Taoyuan, Taiwan. Patients who received PBSCT during the year 2002-2008 in our hospital were recruited. The purpose of the study and procedures involved were fully explained to the participants, and informed consents were obtained. Exclusion criteria tear film deficiency and corneal ulcer. A total of 36 patients were included in our study.

\section{Assessment of dry eye symptoms}

Ocular examination for dry eye syndrome included slit lamp biomicroscopy, fluorescein staining, rose Bengal staining, Schirmer I test, tear break-up time, and questionnaire for dry eye symptoms.

Dry eye was diagnosed using the criteria modified from Hori et al, ${ }^{[7]}$ namely by both the evidence of corneal and conjunctival epithelial damage, and the result of abnormal tear secretion test. For corneal fluorescein staining, the cornea was divided into 5 sectors (central, superior, nasal, temporal and inferior), and a score ranging from 0 to $3(0$ : absent, 1: slightly, 2: moderate, 3: dense punctate staining) was assigned to each sector. These scores were then totaled for the corneal fluorescein staining score. The rose Bengal staining assessed the ocular surface in 5 sectors, including the nasal, superior, temporal and inferior bulbar conjunctiva and the cornea. These zones were graded separately ( $0-3$ for each zone), and these scores were then combined for the total score. Damage of corneal and conjunctival epithelium was detected by corneal fluorescein staining scores of two or greater, and rose Bengal having Schirmer Ia test result of less than $5 \mathrm{~mm}$ or tear break-up time of less than 5 seconds.

To stratify the severity of aqueous tear deficiency, we divided the patients into three groups according to the results of their Schirmer Ia tests (measurement of tear secretion during five minutes of natural blinking without topical anesthetics). Group I patients had less than $5 \mathrm{~mm}$ of wetting the strip. Group II was defined as having Schirmer Ia result between 6 and $9 \mathrm{~mm}$. Patients with Schirmer Ia results of more than $10 \mathrm{~mm}$ were included in Group III.

\section{Control group}

During the period of December 2010 to Jan, 2011, we selected nonhematopoietic transplantation-related patients who visited our outpatient clinic for dry eyes symptoms. The range of age was from 20 to 60s, which was similar to the study group. Because the patients we recruited are relatively younger than the age-related dry eye patients, most of these recruited patients then have some systemic disease or specific ocular condition. The underlying illnesses included Steven-Johnson syndrome, rheumatoid arthritis (RA), ocular cicatricial pemphigoid, systemic lupus erythematosus (SLE), dry eye status post-LASIK treatment and after mentioned above.

\section{Sampling and culture of ocular surface bacteria}

Culture swab samples were taken from the lower conjunctival sac without touching the eyelid margin or lashes by using sterile transport swab (COPAN Italia S.p.A.) that is specific for obtaining aerobic culture. The transport swab was sent to culture room as soon as possible. The majority of bacterial floras on the ocular surface were aerobic as noted in previous studies. ${ }^{[6,7,14-16]}$ For that reason, we used aerobic culture only in this study.

\section{Statistical analysis}

Statistical analysis was performed using SPSS (SPSS for Windows, version 10.0.7C). The frequency of positive culture rate was presented as percentile. Fisher exact test was used for comparison between groups. Comparison of 
the positive culture rate and the rate of dry eye developed between post-PBSCT patients and the control group were performed with Chi-square test or Fisher exact test. The analysis of age difference between groups was performed with one-way ANOVA and $t$ test.

\section{RESULTS}

Thirty-six post-PBSCT patients (16 females and 20 males) were recruited in our study. The underlying hematological malignancies included acute myelogenous leukemia (AML, $n=17$ ), severe aplastic anemia (SAA, $n=5$ ), acute lymphoblastic leukemia (ALL, $n=4$ ), chronic myelogenous leukemia (CML, $n=4)$, non-Hodgkin's lymphoma (NHL, $\mathrm{n}=3$ ), Mantle cell lymphoma (one of the NHLs, $\mathrm{n}=1$ ), natural killer cell lymphoma $(\mathrm{n}=1)$, and multiple myeloma $(\mathrm{MM}, \mathrm{n}=1)$. Age of patients ranged from 23 to 58 years, and the mean age was 38.9 years. The duration from date receiving PBSCT to investigation was ranged from 7 months to 10 years, with a mean of 39.4 months. Nine patients received PBSCT from human leukocyte antigens (HLA) match-unrelated donor (MUD), and the other 27 received from HLA-compatible siblings. All patients were matched with class I and II HLA typings [Table 1].

In the control group, 15 females and 5 males were included with age ranged from 21 to 61 years, and its mean age was 44.9 years [Table 2], which is not statistically different from the mean age of study group ( $p=0.084, t$ test). The numbers of cases of various underlying conditions were as following: Steven-Johnson syndrome $(n=5)$, systemic lupus erythematosus ( $n=3)$, rheumatoid arthritis $(n=2)$, ocular cicatricial pemphigoid $(n=2)$, dry eye post-status of LASIK $(n=2)$, long-term use of idiopathic dry eye $(n=4)$.

\section{Dry eye develops in MUD and match-siblings transplants}

Seven of nine patients receiving MUD transplant developed dry eye (77.8\%), while 15 of match-sibling SCT $(n=27)$ developed dry eye (55.6\%). In this study, patients receiving MUD transplant might have a higher chance of developing dry eye than patients receiving match-sibling donor transplant, but the difference was not statistically significant owing to the small sample size ( $p=0.218$, Fisher exact test).

\section{Bacterial isolation rates}

Group I ( $n=36)$ was defined as having Schirmer Ia test result of $0-5 \mathrm{~mm}$. Bacterial culture of the conjunctival sac were positive in 8 eyes (22\%). Group II $(n=20)$ was defined as having Schirmer Ia result between 6 and $9 \mathrm{~mm}$, and four (20\%) patients in this group were positive for bacterial culture. In Group III $(n=16)$ wherepatients have Schirmer Ia result of $10 \mathrm{~mm}$, and none of the eyes were culturepositive $(0 \%)$. The mean age among the three groups is not statistically different ( $p$-value $=0.285$, one-way ANOVA). The rate of positive culture was higher in group with more severe dry eye although there was not statistically significant between the exact test).

In the nonhematopoietic transplantation-related dry eye group, Schirmer Ia test results were less than $5 \mathrm{~mm}$ in 26 of 40 eyes, $6-9 \mathrm{~mm}$ in 7 eyes, and greater than $10 \mathrm{~mm}$ in the remaining 7 eyes [Table 2]. The total number of positive conjuncitval-sac culture was 12 out of 40 eyes (30\%). We compared the patients with severe dry eye in post-PBSCT (group I) with non hematopoietic transplantation-related dry eyepatients having Schirmer Ia result of less than $5 \mathrm{~mm}$. Eight of 26 eyes had positive culture result in conjunctival swab in the nonhematopoietic transplantation-related group $(30.8 \%)$. Eight of 36 eyes had positive result in post-PBSCT group I (22.2\%), which was less than that of the nonhematopoietic transplantation-related group without statistically significant difference ( $p=0.448$, Chi-square test).

\section{Bacteriological profile}

The bacterial genera identified in post-PBSCT patients (Group I and Group II) included coagulase-negative Staphylococcus sp. $(\mathrm{n}=5)$, Staphylococcus aureus $(\mathrm{n}=3)$,

Table 1: General data of post-PBSCT patients and positive conjuncitval culture rate in each g roup

\begin{tabular}{lcccc}
\hline & Total & Group I & Group II & Group III \\
\hline $\begin{array}{l}\text { Schirmer I value } \\
\text { Sample size }\end{array}$ & 72 & $0-5 \mathrm{~mm}$ & $6-9 \mathrm{~mm}$ & \multicolumn{1}{c}{ mm } \\
(eyes) & & 36 & & 16 \\
Female (eyes) & 32 & 11 & 8 & 7 \\
Male & 40 & 25 & $7(38.9 \%)$ & $2(11.1 \%)$ \\
MUD* & 18 & $9(50 \%)$ & $13(24.1 \%)$ & $14(25.9 \%)$ \\
Match-siblings* & 54 & $27(50 \%)$ & 4 & 0 \\
Positive culture & 12 & 8 & $(20 \%)$ & $(0 \%)$ \\
Rate & $(18 \%)$ & $(22 \%)$ & \\
\hline
\end{tabular}

Abbreviations: MUD: match-unrelated donor; *: Percentage of all match-unrelated donor transplant or all match-siblings transplant 
Corynebacterium sp. $(\mathrm{n}=3)$, Streptococcus pneumonia $(\mathrm{n}=$ 1), Haemophilus influenza $(\mathrm{n}=1)$, Aerococcus viridans $(\mathrm{n}=$ 1), Stenotrophomonas maltophilia $(\mathrm{n}=1)$, and Gram-positive bacilli ( $\mathrm{n}=1)$ [Tables 3 and 4]. Generally, the three most common S. aureus, and Corynebacterium sp. Comparing the bacteriologic profile in the non hematopoietic transplantationrelated group, coagulase-negative Staphylococci $(\mathrm{n}=6)$ was the most common ocular flora. This is followed by Viridans streptococcus $(\mathrm{n}=2)$, Corynebacterium $\mathrm{sp} .(\mathrm{n}=2)$, Chryseobacterium meningosepticum $(\mathrm{n}=2)$, Serratia marcescens and Ps. Aeruginosa $(\mathrm{n}=2)$, all of which have the same culture rate.

\section{DISCUSSION}

In previous surveys, the incidence of dry eye in postSCT patients was $40-60 \%,{ }^{[1,17,18]}$ and the incidence was higher when chronic GVHD developed. ${ }^{[19-21]}$ In the present study, dry eye syndrome develops in $77.8 \%$ ( 7 of 9 patients) of MUD recipients and $55.6 \%$ (15 of 27 patients) of matched sibling transplants. The periductal fibroblasts play a vital role in the pathogenesis of dry eye associated with allogeneic hematopoietic stem cell transplantation, and are involved in both fibrotic and immune processes in the lacrimal glands. ${ }^{[19}$ Mononuclear cells infiltration, adhesion molecules (CD

Table 2: Comparison of the post-PBSCT group and the control group

\begin{tabular}{|c|c|c|c|c|c|c|c|}
\hline & \multirow{2}{*}{$\begin{array}{c}\text { Sample } \\
\text { size (eyes) }\end{array}$} & \multirow{2}{*}{$\begin{array}{c}\text { Age } \\
\text { (Mean) }\end{array}$} & \multicolumn{2}{|c|}{ Gender (eyes) } & \multicolumn{3}{|c|}{ Schirmer Ia value (eyes) } \\
\hline & & & Female & Male & $0-5 \mathrm{~mm}$ & $6-9 \mathrm{~mm}$ & $>10 \mathrm{~mm}$ \\
\hline Post-PBSCT & 72 & $23-58(38.9)$ & 32 & 40 & 36 & 20 & 16 \\
\hline \multirow[t]{3}{*}{ Non-PBSCT } & 40 & $21-61(44.9)$ & 30 & 10 & 26 & 7 & 7 \\
\hline & Total positive & \multicolumn{6}{|c|}{ Culture rate in different Schirmer Ia value. } \\
\hline & culture rate & \multicolumn{2}{|l|}{$0-5 \mathrm{~mm}^{*}$} & \multicolumn{2}{|c|}{$6-9 \mathrm{~mm}^{*}$} & \multicolumn{2}{|c|}{$>10 \mathrm{~mm} *$} \\
\hline Post-PBSCT & $12(18 \%)$ & \multicolumn{2}{|l|}{$8(22 \%)$} & \multicolumn{2}{|c|}{$4(20 \%)$} & \multicolumn{2}{|c|}{$0(0 \%)$} \\
\hline Non-PBSCT & $12(30 \%)$ & \multicolumn{2}{|l|}{$8(30.8 \%)$} & \multicolumn{2}{|c|}{$2(28.8 \%)$} & \multicolumn{2}{|c|}{$2(28.8 \%)$} \\
\hline
\end{tabular}

Abbreviations: PBSCT: Peripheral blood stem cell transplantation; *: The percentile is the positive culture rate in this subgroup.

Table 3: Positive culture in group I

\begin{tabular}{|c|c|c|c|c|}
\hline Age & Gender & Underlying hematologicalmalignancy & Donor source & Identified Genera \\
\hline 55 & M & CML & sibling & Staphylococcus aureus \\
\hline 48 & M & $\begin{array}{l}\text { Mantle cell } \\
\text { lymphoma }\end{array}$ & sibling & Corynebacterium sp. \\
\hline 48 & M & $\begin{array}{l}\text { Mantle cell } \\
\text { lymphoma }\end{array}$ & sibling & $\begin{array}{l}\text { Corynebacterium sp. } \\
\text { Stenotrophomonas maltophilia }\end{array}$ \\
\hline 45 & M & AML & sibling & Staphylococcus aureus \\
\hline 32 & $\mathrm{~F}$ & AML & sibling & Coagulase-negative Staphylococcus \\
\hline 29 & M & $\begin{array}{l}\text { NK cell } \\
\text { lymphoma }\end{array}$ & sibling & Aerococcus viridans \\
\hline 29 & M & $\begin{array}{l}\text { NK cell } \\
\text { lymphoma }\end{array}$ & sibling & $\begin{array}{c}\text { Coagulase-negative Staphylococcus } \\
\text { Gram positive bacilli }\end{array}$ \\
\hline 38 & M & ALL & MUD & $\begin{array}{l}\text { Streptococcus pneumonia } \\
\text { Staphylococcus aureus } \\
\text { Haemophilus influenzae }\end{array}$ \\
\hline
\end{tabular}

Abbreviations: CML: Chronic myelogenous leukemia; AML: acute myelogenous leukemia; NK cell: Natural killer cell; MUD: Match-unrelated donor

Table 4: Positive culture in group II

\begin{tabular}{lcccc}
\hline Age & Gender & Underlying hematologicalmalignancy & Donor source & Identified Genera \\
\hline 26 & F & AML & sibling & Coagulase-negative Staphylococcus \\
25 & F & AML & MUD & Coagulase-negative Staphylococcus \\
58 & F & NHL & sibling & Corynebacterium sp. \\
55 & M & AML & sibling & Coagulase-negative Staphylococcus \\
\hline
\end{tabular}

Abbreviation: NHL: Non-Hodgkin's lymphoma

Biomed J Vol. 35 No. 6

November - December 2012 
54), costimulatory molecules (CD40, CD80, and CD86), and T-cell-derived soluble fibrogenic factors (IL-4, IL-6, and IL-17) are also involved in the disease process. ${ }^{[4,22-25]}$ In addition, total body irradiation and ocular toxicity from bone marrow transplantation. ${ }^{[1,16,26,27]}$

The composition of the normal human ocular surface flora had been identified, and the most prominent ocular flora includes Staphylococcus epidermidis, S. aureus, and Diphtheroids. ${ }^{[28]}$ There are several factors that may alter the composition of ocular surface flora: age, dry eye, immunosuppressive medication and medical illnesses such as diabetes mellitus. Difference in ocular flora among different age groups were noted by Locatcher-Khorazo et al, where Streptococci and pneumococci were found to be more prevalent in the first two decades, and that the prevalence of Gram-negative bacillus increases with age. ${ }^{[29]}$ The number of colony-forming units (CFUs) isolated from patients with dry eye is significantly greater than that isolated from the nondry eye population, but there is no significant difference in the composition of their prominent bacterial genera ${ }^{[6,7]}$ Martins and associates found that the frequency of positive conjunctival cultures is significantly higher in the diabetic group (94.18\%) than the nondiabetic group $(73.33 \%)$. Among diabetic patients, a significantly higher frequency of positive culture rate is detected in those with diabetic retinopathy than in those without. ${ }^{[14]}$ The study by Miller and Ellis revealed a positive correlation between increasing doses of prednisone and the number of bacterial organisms in the patients' conjunctiva. ${ }^{[16]}$ Therefore, the of ocular surface flora.

Human tear film possesses antimicrobial activity. Many components in the tear film such as lysozyme, lactoferrin, tear lipocalin, secretory IgA, and phospholipase A2 contain antimicrobial function. ${ }^{[10]}$ In patients with dry eye syndrome, tear components change in that lactoferrin lysozyme and tear lipocalin are decreased..$^{[30-33]}$

Therefore, it is reasonable that the bacterial colonization rate in ocular surface increases in patients with dry eye when compared with the normal population. Also, the activity of matrix metalloproteinase-9 (MMP-9) is increased in ocular surface of patients with dry eye. MMP-9 accelerates the loss of tight junctions in the superficial corneal epithelial cells. ${ }^{[9]}$ This disruption of the corneal epithelial barrier function increases susceptibility of ocular surface to infection in dry eye patients.

In our study, we found that the positive culture rate of conjunctival sac is correlated with the tear secretion in patients following PBSCT. The positive culture results were higher in Group I (Schirmer Ia test result of 0-5 mm, 22.22\%) and Group II (Schirmer Ia test result of 6-9 mm, $20 \%$ ) than in Group III with Schirmer Ia test result of more than $10 \mathrm{~mm}$, in which all the eyes were culture-negative.
This suggests that tear has the function of washing out and protecting ocular surface against the pathogens. Higher positive culture rate of conjunctiva (30\%, 12 in 40 eyes) in nonresult of greater severity of dry eye in that group, in which $75 \%$ of the patients have Schirmer Ia test results of $0-5 \mathrm{~mm}$. If we compared post-PBSCT patients with the nonhematopoietic transplantation-related group of the same severity of dry eye (Schirmer Ia 0-5 mm), a moderate but insignificant reduction in positive culture rate was found in post-PBSCT patients $(22.22 \%$ vs $30.77 \%, p=0.448)$. Thus despite the implication that post-PBSCT patients are more immunocompromised than the nonhematopoietic transplantation-related group, the conjunctival culture rates are insignificantly affected and consequently not related to the immune status of the patients.

The most prominent ocular surface floras in postPBSCT patients were coagulase-negative Staphylococci, $S$. aureus, and Corynebacterium sp. In the nonhematopoietic transplantation-related group as well as in the post-PBSCT patients, the most common ocular flora is Coagulasenegative Staphylococci. The second most common floras in the two groups were, however, different. It is noted that our small sample size may limit the representation of the true profile of bacterial genera. Nevertheless, the bacterial genera in post-PBSCT patients are similar to the normal population, in which the most common flora were $S$. epidermidis, $S$. aureus, and Corynebacterium diphtheriae ${ }^{[28,34-36]}$ mentioned earlier, there is a large variation of culture-positive rate in the studies of healthy eyes (47-95\%) as well as diseased eyes. ${ }^{[6,14,28,34,35,37]}$ In this study, the positive culture rate in patients with PBSCT-related dry eye and in nonhematopoietic transplantation-related dry eye patients were even lower than that of healthy eyes in the previous study. The difference in the culture methodology and different culture locations may explain the variation. We also noted that the degree of dry eye is more severe in male patients after PBSCT ( 25 out of 40 with Schirmer I test less than $5 \mathrm{~mm}, 62.5 \%$ ) than the female (11 out of 32 with Schirmer I test within 5 $\mathrm{mm}, 34.3 \%)$ presented in our study $(p=0.018$, Chi-square test) [Table 1], although dry eye affects more females than males in general.

The limitations in this study were the relatively small sample size and the characteristics of the patients in the control group. The limited sample size might explain the insignificant difference in culture positive rate among the three groups stratified according to tear secretion. Compared with ordinary dry eye patients, the average age of our patients receiving PBSCT is generally younger (mean: 38.9 y/o). Although dry eye patients are common in our clinics, most of the dry eye is caused by primary lacrimal gland deficiency, which is an age-related disease, and occurs most frequently in older patients. Consequently, younger dry eye 
patients as in our control as rheumatoid arthritis. Therapy for those autoimmune diseases may include immunosuppressive agents, and altered immune status may also produce bias in the ocular surface culture rate. Gender difference is another limitation, as severe dry eye patients after PBSCT are more common in male, while younger dry eye patients affected by autoimmune diseases are predominantly female.

\section{Conclusions}

Our study demonstrates that the bacterial colonization rate in post-PBSCT patients is not different from other dry eye patients. Despite not having statistical significance, there seems to be a positive correlation between the colonization rate and the severity of dry eye. Coagulase-negative Staphylococci is the most common colonizing bacteria of the ocular surface in both the normal population and post-PBSCT patients. The spectrum of conjunctival flora is independent of patient immune status.

\section{REFERENCES}

1. Mencucci R, Rossi FC, Bosi A, Volpe R, Guidi S, Salvi G. Ophthalmological aspects in allogenic bone marrow transplantation: Sjogren-like syndrome in graft-versus-host disease. Eur J Ophthalmol 1997;7:13-8.

2. Hirst LW, Jabs DA, Tutschka PJ, Green WR, Santos GW. The eye in bone marrow transplantation. I. Clinical study. Arch Ophthalmol 1983;101:580-4.

3. Bray LC, Carey PJ, Proctor SJ, Evans RG, Hamilton PJ. Ocular complications of bone marrow transplantation. Br J Ophthalmol 1991;75:611-4.

4. Ogawa Y, Kuwana M, Yamazaki K, Mashima Y, Yamada M, Mori T, et al. Periductal Area as the Primary Site for T-Cell Activation in Lacrimal Gland Chronic Graft-Versus-Host Disease. Invest

5. Ophthalmol Vis Sci 2003;44:1888-96.

6. Jhanji V, Constantinou M, Taylor HR, Vajpayee RB. Microbiological and clinical profiles of patients with microbial keratitis residing in nursing homes. Br J Ophthalmol 2009;93:1639-42.

7. Albietz JM, Lenton LM. Effect of antibacterial honey on the ocular flora in tear deficiency and meibomian gland disease. Cornea 2006;25:1012-9.

8. Hori Y, Maeda N, Sakamoto M, Koh S, Inoue T, Tano Y. Bacteriologic profile of the conjunctiva in the patients with dry eye. Am J Ophthalmol 2008;146:729-34.

9. Graham JE, Moore JE, Jiru X, Moore JE, Goodall EA, Dooley JS, et al. Ocular pathogen or commensal: A PCR-based study of surface bacterial flora in normal and dry eyes. Invest Ophthalmol Vis Sci 2007;48:5616-23

10. Chotikavanich S, de Paiva CS, Li DQ, Chen JJ, Bian F, Farley WJ, et al. Production and Activity of Matrix Metalloproteinase-9 on the Ocular Surface Increase in Dysfunctional Tear Syndrome. Inves Ophthalmol Vis Sci 2009;50:3203-9.

11. Pflugfelder SP, Beuerman RW, Stern ME. Dry eye and ocular surface disorders. New York: Marcel Dekker; 2004.

12. Bourcier T, Thomas F, Borderie V, Chaumeil C, Laroche L. Bacterial keratitis: Predisposing factors, clinical and microbiological review of 300 cases. Br J Ophthalmol 2003;87:834-8.

13. Jeng BH, Gritz DC, Kumar AB, Holsclaw DS, Porco TC, Smith $\mathrm{SD}$, et al. Epidemiology of ulcerative keratitis in Northern California. Arch Ophthalmol 2010;128:1022-8.

14. Kim JH, Kim MK, Oh JY, Jang KC, Wee WR, Lee JH. Outbreak of gram-positive bacterial keratitis associated with epidemic keratoconjunctivitis in neonates and infants. Eye 2009;23:1059-65.

15. Martins EN, Alvarenga LS, Hofling-Lima AL, Freitas D, ZoratYu MC, Farah ME, et al. Aerobic bacterial conjunctival flora in diabetic patients. Cornea 2004;23:136-42.

16. Armstrong RA. The microbiology of the eye. Ophthal Physiol Opt 2000;20:429-41.

17. Miller B, Ellis PP. Conjunctival flora in patients receiving immunosuppressive drugs. Arch Ophthalmol 1977;95:2012-4.

18. Ogawa Y, Kuwana M. Dry eye as a major complication associated with chronic graft-versus-host disease after hematopoietic stem cell transplantation. Cornea 2003;22:S19-27.

19. Ogawa Y, Okamoto S, Wakui M, Watanabe R, Yamada M, Yoshino $\mathrm{M}$, et al. Dry eye after haematopoietic stem cell transplantation. Br J Ophthalmol 1999;83:1125-30.

20. Flowers ME, Parker PM, Johnston LJ, Matos AV, Storer B, Bensinger WI, et al. Comparison of chronic graft-versus-host disease after transplantation of peripheral blood stem cells versus bone marrow in allogeneic recipients: long-term follow-up of a randomized trial. Blood 2002;100:415-9.

21. Carpenter PA. Late effects of chronic graft-versus-host disease. Best Pract Res Clin Haematol 2008;21:309-31.

22. Tichelli A, Duell T, Weiss M, Socie G, Ljungman P, Cohen A, et al. Late-onset keratoconjunctivitis sicca syndrome after bone marrow transplantation: Incidence and risk factors. European Group or Blood and Marrow Transplantation (EBMT) Working Party on Late Effects. Bone Marrow Transplant 1996;17:1105-11.

23. Atamas SP, Luzina IG, Dai H, Wilt SG, White B. Synergy between CD40 ligation and IL-4 on fibroblast proliferation involves IL-4 receptor signaling. J Immunol 2002;168:1139-45.

24. Yamamura Y, Gupta R, Morita Y, He X, Pai R, Endres J, et al. Effector function of resting $\mathrm{T}$ cells: activation of synovial fibroblasts. J Immunol 2001;166:2270-5.

25. Franklin RM, Kenyon KR, Tutschka PJ, Saral R, Green WR, Santos GW. Ocular manifestations of graft-vs-host disease. Ophthalmology 1983;90:4-13.

26. Shahar I, Fireman E, Topilsky M, Grief J, Kivity S, Spirer Z, et al. Effect of IL-6 on alveolar fibroblast proliferation in interstitial lung diseases. Clin Immunol Immunopathol 1996;79:244-51.

27. Fahnehjelm KT, Tornquist AL, Winiarski J. Dry-eye syndrome after allogeneic stem-cell transplantation in children. Acta Opthalmol 2008;86:253-8.

28. Suh DW, Ruttum MS, Stuckenschneider BJ, Mieler WF, Kivlin JD. Ocular findings after bone marrow transplantation in a pediatric population. Ophthalmology 1999;106:1564-70.

29. Fahmy JA, Moller S, Bentzon MW. Bacterial flora in relation to cataract extraction. I. Material, methods and preoperative flora. Acta Ophthalmologica 1975;53:458-75.

30. Locatcher-Khorazo D, Seegal BC. The bacterial flora of the healthy eye. Microbiology of the Eye. 1st ed. St. Louis: Mosby; 1972. p. 13-23.

31. Zhou L, Beuerman RW, Chan CM, Zhao SZ, Li XR, Yang H, et al. Identification of tear fluid biomarkers in dry eye syndrome using

Biomed J Vol. 35 No. 6

November - December 2012 
iTRAQ quantitative proteomics. J Proteome Res 2009;8:4889-905.

32. Caffery B, Joyce E, Boone A, Slomovic A, Simpson T, Jones L, et al. Tear lipocalin and lysozyme in Sjogren and non-Sjogren dry eye. Optom Vis Sci 2008;85:661-7.

33. Wang HF, Fukuda M, Shimomura Y. Diagnosis of dry eye. Semin Ophthalmol 2005;20:53-62.

34. Ohashi Y, Ishida R, Kojima T, Goto E, Matsumoto Y, Watanabe K, et al. Abnormal protein profiles in tears with dry eye syndrome. Am J Ophthalmol 2003;136:291-9.

35. de Caro JJ, Ta CN, Ho HK, Cabael L, Hu N, Sanislo SR, et al. Bacterial contamination of ocular surface and needles in patients undergoing intravitreal injections. Retina 2008;28:877-83.

36. McNatt J, Allen SD, Wilson LA, Dowell VR, Jr. Anaerobic flora of the normal human conjunctival sac. Arch Ophthalmol 1978;96:1448-50.

37. Capriotti JA, Pelletier JS, Shah M, Caivano DM, Ritterband DC. Normal ocular flora in healthy eyes from a rural population in Sierra Leone. Int Ophthalmol 2009;29:81-4.

38. Mela EK, Drimtzias EG, Christofidou MK, Filos KS, Anastassiou ED, Gartaganis SP. Ocular surface bacterial colonisation in sedated intensive care unit patients. Anaesth Intensive Care 2010;38:190-3. 